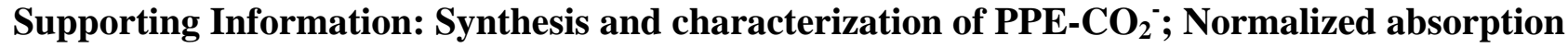 and emission of PPE- $\mathrm{CO}_{2}^{-}$in water and methanol.
}

\section{Amplified Fluorescence Quenching of a Conjugated Polyelectrolyte Mediated by $\mathrm{Ca}^{2+}$}

Hui Jiang, Xiaoyong Zhao, and Kirk S. Schanze*

Department of Chemistry, University of Florida, PO Box 117200, Gainesville, FL 32611-7200

PPE- $\mathrm{CO}_{2} \mathbf{C}_{12} \mathbf{H}_{25}$. As shown in Scheme S1, a solution of 2,5-bis(dodecyloxycarbonylmethoxy)-1,4-diiodobenzene $\quad\left(\begin{array}{llll}204 & \mathrm{mg}, & 0.25 & \mathrm{mmol}\end{array}\right)$ and 1,4-diethynylbenzene (32 mg, $0.25 \mathrm{mmol})$ in $10 \mathrm{~mL}$ of dry $\mathrm{THF} / \mathrm{Et}_{3} \mathrm{~N}(\mathrm{v}: \mathrm{v}=2: 1)$ was outgassed with argon for 15 minutes. Then $8.7 \mathrm{mg}$ of $\mathrm{Pd}\left(\mathrm{PPh}_{3}\right)_{4}(7.5 \mu \mathrm{mol})$ and $1.4 \mathrm{mg}$ of $\mathrm{CuI}(7.5 \mu \mathrm{mol})$ were added under argon. The reaction was stirred at $60{ }^{\circ} \mathrm{C}$ for 18 hours. The obtained viscous suspension was poured into $150 \mathrm{~mL}$ of methanol, resulting in the precipitation of the ester precursor polymer as light yellow fibers. The polymer was further purified by two repeated cycles of dissolution in THF and precipitation in methanol. Yield: $135 \mathrm{mg}(79 \%) .{ }^{1} \mathrm{H}$ NMR $\left(\mathrm{CDCl}_{3}\right): \delta=0.88(\mathrm{br}, \mathrm{t}, 3 \mathrm{H}), 1.25(\mathrm{br}, \mathrm{m}$, 36H), 1.68 (br, m, 4H), 4.24 (br, m, 4H), 4.74 (br, s, 4H), 7.02 (br, s, 2H), 7.56 (br, s, 4H). GPC (THF, polystyrene standards): $\mathrm{M}_{\mathrm{n}} \approx 127 \mathrm{~kg}-\mathrm{mol}^{-1}, \mathrm{M}_{\mathrm{w}} \approx 286 \mathrm{~kg}-\mathrm{mol}^{-1}(\mathrm{PDI}=2.25)$.

PPE- $\mathrm{CO}_{2}{ }^{-}$. To a solution of $135 \mathrm{mg}$ of PPE- $\mathrm{CO}_{2} \mathrm{C}_{12} \mathrm{H}_{25}(0.20 \mathrm{mmol})$ in $30 \mathrm{~mL}$ of dioxane/THF (v:v $=5: 1)$ was added $1.5 \mathrm{~mL}$ of $1 \mathrm{M}(\mathrm{n}-\mathrm{Bu})_{4} \mathrm{~N}^{+} \mathrm{OH}^{-}$in methanol, and the resulting mixture was stirred at room temperature for 24 hours. During the course of the hydrolysis reaction, $2 \mathrm{~mL}$ of water were systematically added in order to keep the solution clear. Then a solution of $0.20 \mathrm{~g}$ of $\mathrm{NaClO}_{4}(1.6 \mathrm{mmol})$ in $3 \mathrm{~mL}$ of water was added to the hydrolyzed polymer solution, and the resulting mixture was poured into $400 \mathrm{~mL}$ of cold acetone, resulting in the precipitation of $\mathrm{PPE}^{-\mathrm{CO}_{2}}{ }^{-}$as a fine yellow powder. The polymer was then dissolved in $50 \mathrm{~mL}$ of deionized water and the material was purified by dialysis into deionized water using a regenerated cellulose membrane (12 kD MWCO). After dialysis, the polymer 
solution was filtered through $1.0 \mu \mathrm{m}$ glass fiber filter (Fisher Scientific) and stored as a stock solution.

${ }^{1} \mathrm{H}$ NMR $\left(\mathrm{D}_{2} \mathrm{O}\right): \delta=4.99-5.11(\mathrm{br}, \mathrm{s}, 4 \mathrm{H}), 7.35$ (br, s, 2H), 7.88 (br, s, 4H).

\section{Scheme S1}
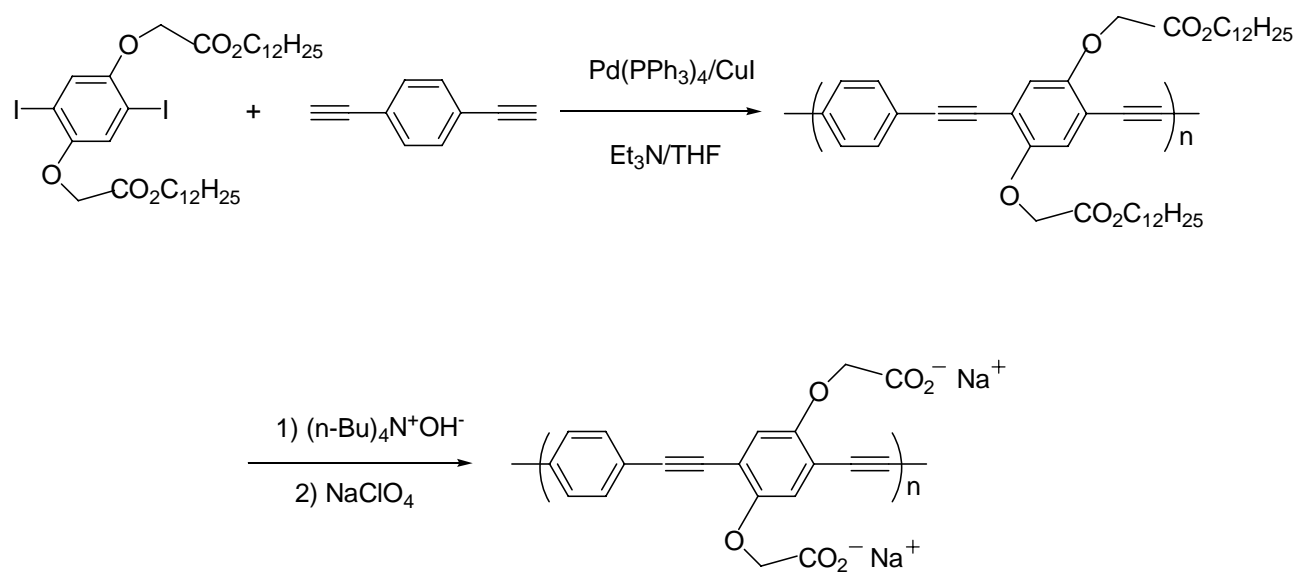


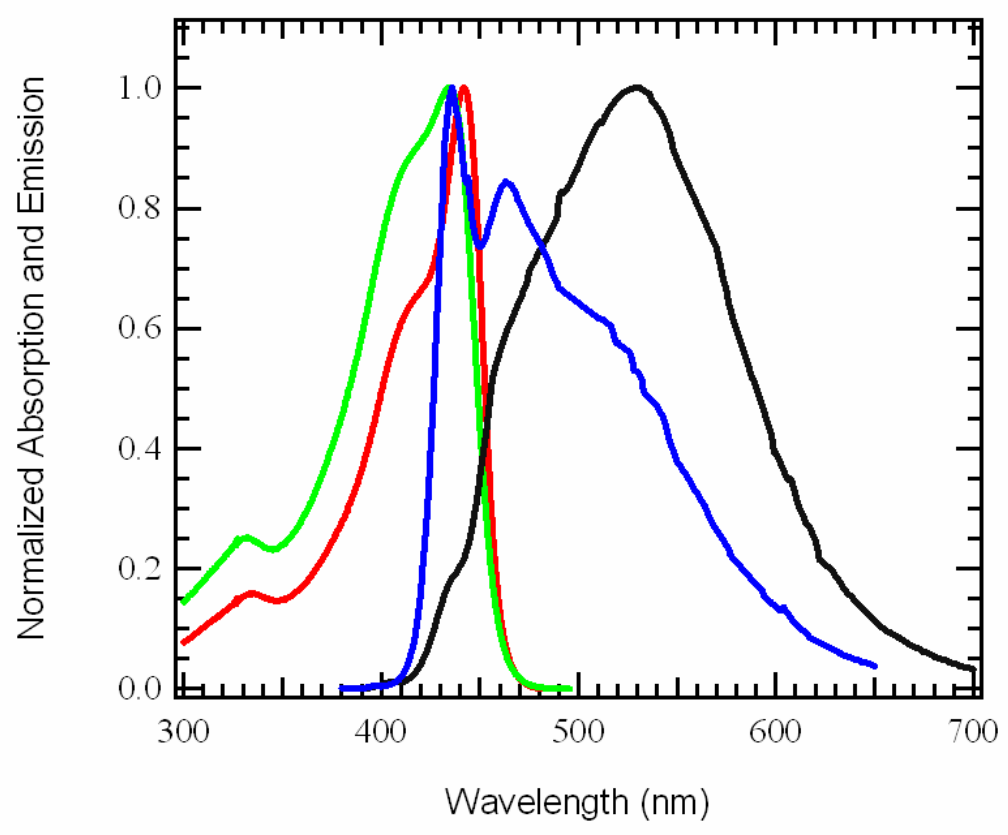

Figure S1. Normalized absorption and emission of PPE- $\mathrm{CO}_{2}^{-}$in water and methanol. —: Absorption in water; —: Emission in water; —: Absorption in methanol; —: Emission in methanol. 